\title{
ANIONIC AND ZWITTERIONIC PHOTOPHYSICAL EFFECTS IN SOME PYRIDINIUM OXAZOLE LASER DYES
}

\author{
R. F. KUBIN, R. A. HENRY, M. E. PIETRAK and D. E. BLISS \\ Chemistry Division, Research Department Naval Weapons Center, \\ China Lake, CA 93555 \\ J. H. HALL $\dagger$ \\ Department of Chemistry and Biochemistry, Southern Illinois University, \\ Carbondale, IL 62901
}

(Received 24 July 1989; in final form 2 January 1990)

\begin{abstract}
Kauffman and Bentley [Laser Chem. 8, 49-59 (1988)] have reported increased laser output by changing the anion of certain pyridinium oxazole dyes from the tosylate to the mesylate salt. Likewise, zwitterion variants of these dyes are also reported to have a significantly improved laser output. We find anion changes to be modest and, with one exception, all zwitterions tested were no better or not as good as the tosylate salt with respect to lasing output. However, both the mesylate salt and the zwitterion variants have greatly improved lifetimes if there is no fluorine auxochrome in the basic dye. These authors also report observation of bifurcated lasing output curves. We see no such phenomena.
\end{abstract}

\section{INTRODUCTION}

1-methyl-4-[5-(4-methoxyphenyl)-2-oxazolyl]pyridinium $p$-toluenesulfonate (called Ox 2) was the first very long-lived, moderate output dye observed in our laboratory. ${ }^{1}$ Recently Kauffman and Bentley ${ }^{2}$ (K-B) found that in methanol the mesylate salt of Ox 2 has about twice the output of the tosylate salt and a sulfopropyl zwitterion form has about 2.5 times the output of the tosylate salt. Because the pyridinium oxazole dyes are salts, the solvent plays an important part in the photophysical properties of the dye. Certainly, the possibility exists that different anions and solvent interaction could also change the photophysical properties of the dye. In the past we have not observed any strong effects due to changing the anion between perchlorate and tosylate. ${ }^{3}$

\section{EXPERIMENTAL}

Our dye laser system is a flashlamp-pumped Phase-R DL 10Y laser head in a triaxial configuration. The cavity has an approximate $100 \%$ reflector wideband rear mirror

$\dagger$ Deceased. 
and we use output couplers with 20 to $90 \%$ reflectivity. The flashlamp cooling jacket contains a $0.1 \%$ caffeine/water solution which cuts off UV radiation for wavelengths shorter than $295 \mathrm{~nm}$. For many of the dyes we have tested, an output coupler of $50 \%$ reflectivity is near the peak of the output curve at our usual operational temperature of $27.3^{\circ} \mathrm{C}$. Temperature of coolant and dye solutions can be controlled separately to $0.01^{\circ} \mathrm{C} .{ }^{4}$ The laser beam is wavelength analyzed in a 3/4 meter Spex model 1702 spectrometer. Quantum yield measurements were made using a Spex F222 fluo-

Table 1 The pyridinium oxazole dyes discussed in this paper

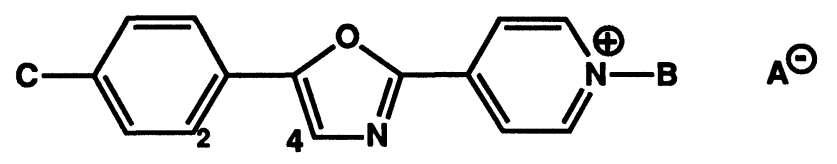

\begin{tabular}{|c|c|c|c|c|c|}
\hline Dye & A & B & C & 2 & 4 \\
\hline $\mathrm{O} \times 2^{a}$ & tosylate & methyl & methoxy & $\mathbf{H}$ & $\mathbf{H}$ \\
\hline Ox $2 A$ & mesylate & methyl & methoxy & $\mathbf{H}$ & $\mathbf{H}$ \\
\hline Ox $2 Z 3$ & \multicolumn{2}{|c|}{ sulfopropyl zwitterion $b$} & methoxy & $\mathbf{H}$ & $\mathbf{H}$ \\
\hline Ox $12^{a}$ & tosylate & methyl & methoxy & \multicolumn{2}{|c|}{ ethylene bridge } \\
\hline Ox $13^{a}$ & tosylate & methyl & $\mathbf{H}$ & $\mathbf{H}$ & $\mathbf{H}$ \\
\hline Ox $13 A^{a}$ & perchlorate & methyl & $\mathbf{H}$ & $\mathbf{H}$ & $\mathbf{H}$ \\
\hline Ox $15^{a}$ & tosylate & methyl & $\mathbf{H}$ & \multirow{3}{*}{\multicolumn{2}{|c|}{$\begin{array}{l}\text { vinylene bridge } \\
\text { ethylene bridge } \\
\text { ethylene bridge }\end{array}$}} \\
\hline Ox $16^{a}$ & perchlorate & methyl & $\mathbf{F}$ & & \\
\hline Ox $16 Z 3$ & \multicolumn{2}{|c|}{ sulfopropyl zwitterion $b$} & $\mathbf{F}$ & & \\
\hline Ox $17^{a}$ & perchlorate & methyl & $\mathbf{H}$ & $\mathbf{H}$ & phenyl \\
\hline Ox 17A & tosylate & methyl & $\mathbf{H}$ & $\begin{array}{l}2,2 \text { ' bridge } \\
\text { phenyl }\end{array}$ & phenyl ${ }^{c}$ \\
\hline Ox 17AA & mesylate & methyl & $\mathbf{H}$ & $\begin{array}{l}2,2^{\prime} \text { bridge } \\
\text { phenyl }\end{array}$ & phenylc \\
\hline Ox 17AZ3 & \multicolumn{2}{|c|}{ sulfopropyl zwitterion $b$} & $\mathbf{H}$ & $\begin{array}{l}2,2^{\prime} \text { bridge } \\
\text { phenyl }\end{array}$ & phenyl $c$ \\
\hline Ox $20^{a}$ & tosylate & methyl & $\mathbf{H}$ & $\mathbf{H}$ & methyl \\
\hline Ox $20 \mathrm{Z3}$ & \multicolumn{2}{|c|}{ sulfopropyl zwitterion $b$} & $\mathbf{H}$ & $\mathbf{H}$ & methyl \\
\hline Ox $21^{a}$ & tosylate & methyl & $\mathbf{F}$ & $\mathbf{H}$ & methyl \\
\hline Ox $21 Z 3$ & \multicolumn{2}{|c|}{ sulfopropyl zwitterion $b$} & $\mathbf{F}$ & $\mathbf{H}$ & methyl \\
\hline Ox 27A & mesylate & methyl & n-butoxy & $\mathbf{H}$ & $\mathbf{H}$ \\
\hline Ox $27 Z 3$ & \multicolumn{2}{|c|}{ sulfopropyl zwitterion $b$} & n-butoxy & $\mathbf{H}$ & $\mathrm{H}$ \\
\hline
\end{tabular}

aDyes reported in Ref. 3.

${ }^{b}$ This means the structure

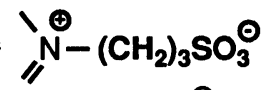

'This means the structure

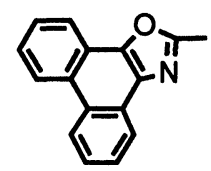


rometer with quinine sulfate as the comparison standard. For the latter measurements, the dye concentrations were in the $10^{-7} \mathrm{M}$ range with peak absorbances $\leq 0.014$. For the laser tests, concentrations were $2.0 \times 10^{-4} \mathrm{M}$ unless otherwise noted.

Tables 1-5 (discussed below) list the dyes studied and the properties measured under various conditions. However, because we wish to compare our data with previous results, the data in Table 3, which contains the lasing parameters for the dyes tested, were determined under the same conditions as in Ref. 3 (and references cited therein). Thus, the cavity parameters, including the output coupler, were the same.

\section{RESULTS}

The basic dye molecule is shown in Table 1 with substitutions germane to our discussion. The short form nomenclature is as in Ref. 3. Based on the results of K-B,

Table 2 Energy output of laser dyes related to the basic pyridinium oxazole dye. The cover gas is argon

\begin{tabular}{|c|c|c|c|c|c|c|c|}
\hline \multirow[t]{2}{*}{ Dye } & \multirow[t]{2}{*}{ Solvent } & \multicolumn{2}{|c|}{ Energy } & \multirow[t]{2}{*}{ Dye } & \multirow[t]{2}{*}{ Solvent } & \multicolumn{2}{|c|}{ Energy } \\
\hline & & In, $\mathrm{J}$ & Out, $\mathrm{mJ}$ & & & In, J & Out, mJ \\
\hline Ox 2 & $\mathrm{EtOH}$ & 50 & 34.7 & Ox 17 & $\mathrm{EtOH}$ & 60 & 19.1 \\
\hline $\mathrm{Ox} 2 \mathrm{~A}$ & $\mathrm{EtOH}$ & 60 & 86.5 & Ox 17A & $\mathrm{EtOH} / \mathrm{H}_{2} \mathrm{O}$ & 60 & 33.1 \\
\hline Ox 2 & $\mathrm{EtOH} / \mathrm{H}_{2} \mathrm{O}$ & 40 & 36.4 & Ox 20 & $\mathrm{EtOH}$ & 55 & 37.4 \\
\hline $\mathrm{Ox} 2 \mathrm{~A}$ & $\mathrm{EtOH} / \mathrm{H}_{2} \mathrm{O}$ & 60 & 76.9 & Ox $20 Z 3$ & $\mathrm{EtOH}$ & 60 & 24.7 \\
\hline Ox $2 Z 3$ & $\mathrm{EtOH} / \mathrm{H}_{2} \mathrm{O}$ & 60 & 106.3 & & $\mathrm{EtOH} / \mathrm{H}_{2} \mathrm{O}$ & 60 & 37.8 \\
\hline & & & & & $\mathrm{H}_{2} \mathrm{O}$ & 60 & 30.7 \\
\hline Ox 12 & $\mathrm{EtOH}$ & 35 & 41.0 & Ox 21 & $\mathrm{EtOH}$ & 55 & 42.2 \\
\hline & & & & Ox $21 Z 3$ & $\mathrm{EtOH}$ & 60 & 40.3 \\
\hline & & & & & $\mathrm{EtOH} / \mathrm{H}_{2} \mathrm{O}$ & 60 & 65.8 \\
\hline & & & & & $\mathrm{H}_{2} \mathrm{O}$ & 60 & 30.0 \\
\hline Ox 13 & $\mathrm{EtOH}$ & 45 & 37.5 & Ox 27A & $\mathrm{EtOH}$ & 60 & 76.9 \\
\hline Ox 13A & $\mathrm{EtOH}$ & 45 & 44.9 & Ox $27 Z 3$ & $\mathrm{EtOH}$ & 60 & 58.3 \\
\hline & & & & & $\mathrm{EtOH} / \mathrm{H}_{2} \mathrm{O}$ & 60 & 83.1 \\
\hline Ox 16 & $\mathrm{EtOH}$ & 60 & 30.7 & & & & \\
\hline Ox $16 Z 3$ & $\mathrm{EtOH}$ & 60 & 60.7 & & & & \\
\hline & $\mathrm{EtOH} / \mathrm{H}_{2} \mathrm{O}$ & 60 & 80.5 & & & & \\
\hline & $\mathrm{H}_{2} \mathrm{O}$ & 60 & 31.2 & & & & \\
\hline
\end{tabular}


Table 3 Comparison of lasing parameters for dyes in this study with prior work. The cover gas is argon. $\mathrm{K}$ is the slope efficiency, $\mathrm{t}$ is lasing threshold, 1/C the lifetime, and FOM the figure of merit

\begin{tabular}{|c|c|c|c|c|c|}
\hline Dye & Solvent & $10^{3} \mathrm{~K}$ & $t, J$ & $1 / \mathrm{C} \mathrm{MJ} / \mathrm{\ell}$ & $\mathrm{FOM} \mathrm{kJ/ \ell}$ \\
\hline $\begin{array}{l}O \times 2^{a} \\
\text { Ox } 2 A \\
\text { Ox } 2 Z 3\end{array}$ & $\begin{array}{l}\text { EtOH } \\
\text { EtOH } \\
\text { EtOH }\end{array}$ & $\begin{array}{l}1.53 \\
2.05 \\
1.55\end{array}$ & $\begin{array}{l}22.1 \\
18.9 \\
32.9\end{array}$ & $\begin{array}{c}10,000 \\
>>10,000 \\
>>10,000\end{array}$ & $\begin{array}{c}15,300 \\
\ldots- \\
--\end{array}$ \\
\hline $\begin{array}{l}\text { Ox } 2^{a} \\
\text { Ox } 2 A \\
\text { Ox } 2 Z 3 \\
\text { Ox } 2 Z 3\end{array}$ & $\begin{array}{c}\mathrm{EtOH} / \mathrm{H}_{2} \mathrm{O} \\
\mathrm{EtOH} / \mathrm{H}_{2} \mathrm{O} \\
\mathrm{EtOH} / \mathrm{H}_{2} \mathrm{O} \\
\mathrm{H}_{2} \mathrm{O}\end{array}$ & $\begin{array}{l}2.63 \\
2.29 \\
2.57 \\
1.59\end{array}$ & $\begin{array}{l}26.2 \\
26.7 \\
18.7 \\
33.9\end{array}$ & $\begin{array}{c}438 \\
\gg>10,000 \\
>>10,000 \\
---\end{array}$ & $\begin{array}{c}1,152 \\
--- \\
-- \\
---\end{array}$ \\
\hline $\begin{array}{l}\text { Ox } 12^{a} \\
\text { Ox } 12^{a}\end{array}$ & $\begin{array}{c}\mathrm{EtOH} \\
\mathrm{EtOH} / \mathrm{H}_{2} \mathrm{O}\end{array}$ & $\begin{array}{l}3.00 \\
3.60\end{array}$ & $\begin{array}{l}21.8 \\
21.5\end{array}$ & $\begin{array}{l}188 \\
219\end{array}$ & $\begin{array}{l}564 \\
788\end{array}$ \\
\hline $\begin{array}{l}\text { Ox } 13^{a} \\
\text { Ox } 13 A^{a}\end{array}$ & $\begin{array}{l}\mathrm{EtOH} \\
\mathrm{EtOH}\end{array}$ & $\begin{array}{l}1.64 \\
1.84\end{array}$ & $\begin{array}{l}22.5 \\
22.1\end{array}$ & $\begin{array}{l}3.2 \\
1.7\end{array}$ & $\begin{array}{l}5.2 \\
3.1\end{array}$ \\
\hline Ox $15^{a}$ & $\mathrm{EtOH}$ & 1.29 & 25.8 & 10,000 & 12,900 \\
\hline $\begin{array}{l}\text { Ox } 16 \\
\text { Ox } 16 Z 3\end{array}$ & $\begin{array}{l}\text { EtOH } \\
\text { EtOH }\end{array}$ & $\begin{array}{l}0.85 \\
1.77\end{array}$ & $\begin{array}{l}26.8 \\
22.2\end{array}$ & $\begin{array}{l}61.0 \\
25.2\end{array}$ & $\begin{array}{l}52.0 \\
44.6\end{array}$ \\
\hline $\begin{array}{l}\text { Ox 17a } \\
\text { Ox 17A }\end{array}$ & $\begin{array}{c}\mathrm{EtOH} \\
\mathrm{EtOH} / \mathrm{H}_{2} \mathrm{O}\end{array}$ & $\begin{array}{l}0.64 \\
0.89\end{array}$ & $\begin{array}{l}29.1 \\
21.4\end{array}$ & $\begin{array}{c}18.0 \\
0.005\end{array}$ & $\begin{array}{c}12.0 \\
0.004\end{array}$ \\
\hline $\begin{array}{l}\text { Ox 20a } \\
\text { Ox 20Z3 }\end{array}$ & $\begin{array}{l}\text { EtOH } \\
\text { EtOH }\end{array}$ & $\begin{array}{l}1.57 \\
0.71\end{array}$ & $\begin{array}{l}26.8 \\
23.9\end{array}$ & $\begin{array}{c}704 \\
>10,000\end{array}$ & $\begin{array}{c}1,106 \\
---\end{array}$ \\
\hline $\begin{array}{l}\text { Ox } 21^{a} \\
\text { Ox } 21 \mathrm{Z} 3\end{array}$ & $\begin{array}{l}\text { EtOH } \\
\text { EtOH }\end{array}$ & $\begin{array}{l}1.63 \\
1.13\end{array}$ & $\begin{array}{l}26.0 \\
21.0\end{array}$ & $\begin{array}{c}10,000 \\
1,493\end{array}$ & $\begin{array}{c}16,300 \\
1,687\end{array}$ \\
\hline RHO 6G TFB $b$ & $\mathrm{EtOH}$ & 3.35 & 15.9 & 345 & 1,200 \\
\hline
\end{tabular}

aTaken from Ref. 3.

$b$ Taken from Ref. 7.

Kauffman ${ }^{5}$ suggested that we make the zwitterion dye form for Ox 2 by quaternizing the pyridyl nitrogen with the propane sultone. He also suggested synthesis and testing of the mesylate salts. Table 2 lists the observed energy output for the dyes we used, as well as some comparison data. ${ }^{3}$ Because of the coating on the cavity rear mirror, it was not always possible to input $60 \mathrm{~J}$ when the output was expected to exceed approximately $50 \mathrm{~mJ}$. In the discussion we have used the measured slope efficiency and threshold to estimate the output at $60 \mathrm{~J}$ input using the relationship ${ }^{6}$

$$
\varphi=k(I-t)[\mathrm{J}]
$$

$\varphi$ is the output in joules, $k$ the slope efficiency, $I$ the input in joules, and $t$ the threshold for lasing in joules. Table 2 shows that the zwitterions, with the exception of $\mathrm{Ox} 2 \mathrm{Z3}$ and $\mathrm{Ox} 16 \mathrm{Z3}$, do not perform any better than or as well as the tosylate salt. 
Ox $2 Z 3$ had the highest output of any dye we have observed. Under the same conditions, rhodamine 590 chloride output was $100.2 \mathrm{~mJ}$.

Table 3 lists the calculated lasing parameters in ethanol and/or ethanol:water (50:50 by volume). Rhodamine $6 \mathrm{G}$ tetrafluoroborate is included for comparison; ${ }^{7}$ these data would indicate a large output at $60 \mathrm{~J}$ input in ethanol. That measurement has not been made.

We find in ethanol, which should be similar to methanol, that the mesylate salt has about 1.5 times the output of the tosylate, but the sulfopropyl zwitterion only has

Table 4 Lasing bands for dyes we have studied

\begin{tabular}{|c|c|c|}
\hline Dye & Solvent & Band, nm \\
\hline Ox $2 A$ & $\begin{array}{c}\text { EtOH - Air } \\
\text { EtOH - Argon }\end{array}$ & $\begin{array}{l}554-579 \\
553-587\end{array}$ \\
\hline$O \times 2 A$ & $\begin{array}{c}\mathrm{EtOH} / \mathrm{H}_{2} \mathrm{O} \text { - Air } \\
\text { EtOH/H} / \mathrm{H}_{2} \mathrm{O} \text { - Argon }\end{array}$ & $\begin{array}{l}565-592 \\
559-592\end{array}$ \\
\hline Ox $2 Z 3$ & $\begin{array}{c}\mathrm{EtOH} / \mathrm{H}_{2} \mathrm{O}-\mathrm{Air} \\
\mathrm{EtOH} / \mathrm{H}_{2} \mathrm{O}-\text { Argon }\end{array}$ & $\begin{array}{l}562-591 \\
562-591\end{array}$ \\
\hline Ox $16 Z 3$ & $\begin{array}{l}\mathrm{EtOH} / \mathrm{H}_{2} \mathrm{O} \text { - Air } \\
\text { EtOH/H} / \mathrm{H}_{2} \mathrm{O} \text { - Argon }\end{array}$ & $\begin{array}{l}525-545 \\
525-544\end{array}$ \\
\hline Ox $16 Z 3$ & $\begin{array}{c}\mathrm{H}_{2} \mathrm{O}-\mathrm{Air} \\
\mathrm{H}_{2} \mathrm{O}-\text { Argon }\end{array}$ & $\begin{array}{l}526-553 \\
525-553\end{array}$ \\
\hline Ox $20 Z 3$ & $\begin{array}{c}\text { EtOH - Air } \\
\text { EtOH - Argon }\end{array}$ & $\begin{array}{l}501-519 \\
501-520\end{array}$ \\
\hline Ox $20 \mathrm{Z} 3$ & $\begin{array}{l}\mathrm{EtOH} / \mathrm{H}_{2} \mathrm{O} \text { - Air } \\
\text { EtOH/H } 2 \mathrm{O} \text { - Argon }\end{array}$ & $\begin{array}{l}502-521 \\
503-522\end{array}$ \\
\hline Ox $20 \mathrm{Z} 3$ & $\mathrm{H}_{2} \mathrm{O}-\mathrm{Air}$ & $501-524$ \\
\hline Ox $21 Z 3$ & $\begin{array}{c}\text { EtOH - Air } \\
\text { EtOH - Argon }\end{array}$ & $\begin{array}{l}500-519 \\
500-520\end{array}$ \\
\hline Ox $21 Z 3$ & $\begin{array}{l}\mathrm{EtOH} / \mathrm{H}_{2} \mathrm{O}-\mathrm{Air} \\
\mathrm{EtOH} / \mathrm{H}_{2} \mathrm{O} \text { - Argon }\end{array}$ & $\begin{array}{l}503-523 \\
503-524\end{array}$ \\
\hline Ox $21 Z 3$ & $\begin{array}{c}\mathrm{H}_{2} \mathrm{O} \text { - Air } \\
\mathrm{H}_{2} \mathrm{O} \text { - Argon }\end{array}$ & $\begin{array}{l}504-526 \\
504-526\end{array}$ \\
\hline Ox 27A & $\begin{array}{c}\text { EtOH - Air } \\
\text { EtOH - Argon }\end{array}$ & $\begin{array}{l}556-585 \\
564-592\end{array}$ \\
\hline Ox $27 Z 3$ & $\begin{array}{l}\mathrm{EtOH} / \mathrm{H}_{2} \mathrm{O}-\mathrm{Air} \\
\mathrm{EtOH} / \mathrm{H}_{2} \mathrm{O} \text { - Argon }\end{array}$ & $\begin{array}{l}566-592 \\
569-593 \\
\end{array}$ \\
\hline
\end{tabular}


Table 5 Absorption and emission wavelength maxima and fluorescence quantum yields for selected pyridinium oxazole dyes in ethanol under air. Ox 17AZ3 is in ethanol/water 50/50 by volume

\begin{tabular}{l|c|c|c}
\hline Dye & $\begin{array}{c}\text { Abs. peak, } \\
\mathrm{nm}\end{array}$ & $\begin{array}{c}\text { Em. peak, } \\
\mathrm{nm}\end{array}$ & FQY \\
\hline Ox 2 & 410 & 567 & 0.73 \\
Ox 2A & 411.2 & 565 & 0.76 \\
Ox 2Z3 & 409.7 & 563 & 0.92 \\
Ox 16Z3 & 417.7 & 520 & 0.86 \\
Ox 20Z3 & 389.7 & 491 & 1.03 \\
Ox 21Z3 & 387.0 & 495 & 1.01 \\
Ox 27 & 411.2 & 571 & 0.83 \\
Ox 27Z3 & 411.8 & 567 & 0.91 \\
Ox 17A & 410.6 & 534 & 0.99 \\
Ox 17AA & 412.2 & 532 & 0.85 \\
Ox 17AZ3 & 412.2 & 533 & 1.02 \\
Ox 12 & 452.2 & 584 & 0.65 \\
\hline
\end{tabular}

approximately the same output as the tosylate salt. However, both of these variations of Ox 2 exhibit even longer life times than Ox 2. By changing solvent to ethanol:water (50:50 by volume), we find that the tosylate salt has the largest slope efficiency of the three variants. Were it not for a large decrease in the threshold for lasing of the sulfopropyl zwitterion, the ordering by output would be tosylate $>$ zwitterion $>$ mesylate. Instead we observe zwitterion $>$ tosylate $>$ mesylate. However, the difference between the tosylate and mesylate salts is only about $16 \%$. This difference in output is about the same order of magnitude we have found between perchlorate and tosylate anions with perchlorate being the larger. These observations lead us to our original conclusion that, in general, no strong effects on output are noticed by changing the dye anion among those tested on the pyridinium oxazole dyes in the polar solvents we have been using.

However, we also note that in changing solvents from ethanol to ethanol:water the lifetimes of the mesylate and zwitterion variants of $\mathrm{Ox} 2$ remain large while $\mathrm{Ox} 2$ itself drops by a factor of almost 25 . Peculiar to the zwitterion variant of $\mathrm{Ox} 2$ among the zwitterion dye variants in this study is its high output, actually exceeding that of rhodamine 590 chloride.

Measurement of the fluorescence quantum yields shows a strong effect of making the zwitterions of these dyes. Table 5 lists the measured quantum yields along with their absorption and emission maxima. For one of the two cases where all dye variants (mesylate, tosylate, zwitterion) were made, there is essentially no difference in quantum yield between $\mathrm{O} 2 \mathrm{2}$ and $\mathrm{O} \times 2 \mathrm{~A}$. However, the zwitterionic dyes have high fluorescence quantum yields, even if the tosylate salt does not. For the Ox 17A series, the mesylate salt (Ox 17AA) appears to have a somewhat lower fluorescence quantum yield than the tosylate. However, the zwitterion (Ox 17AZ3) again has the apparent characteristically high quantum yield. 
Figures 1-3 show some of the spectrometer films taken for determination of the dye tuning range. In order to measure the upper and lower wave length extremities, 6 to 10 shots were fired because of the small fraction of light diverted to the spectrometer. The pictures are thus, in a sense, composites. However, it is clear that there is no null in the lasing bands for the same dyes studied by K-B nor in any of the other new dyes. Figure 4 shows a series of single shots over a range of 35 to $60 \mathrm{~J}$ input energies for the dye Ox $16 \mathrm{Z} 3$ as typical for these dyes. In Figure $1 \mathrm{a}$ the dye is $\mathrm{Ox} 2$ in methanol (under argon), the same solvent as used by K-B. Figures 1b-e are for the mesylate salt of Ox 2 . These photographs show the effect of the removal of oxygen on the lasing band. Under argon the lasing band increases, sometimes markedly, and there is generally improved performance. With the zwitterionic dye forms the lasing band does not change under air or argon as exemplified in Figures $1 \mathrm{f}$ and $\mathrm{g}$. Figures 2 and 3 show the lasing bands for the remainder of the zwitterions studied. For these latter figures, the output coupler was $55 \%$ reflective instead of $80 \%$ as in Fig. 1. Independent of output, the lasing band is broader the greater the reflectivity of the output coupler. Table 4 tabulates the lasing bands for the dyes.

\section{DISCUSSION}

We have found that solvent and auxochrome substitution on the pyridinium oxazole to be of larger effect on the photophysical properties of the dyes than changes in the anion. We feel that in the dyes without fluorine in position $\mathrm{C}$, the zwitterionic dye form (using the propane sultone to make the zwitterion) results in an improved dye having a very long lifetime and, at least for $\mathrm{Ox} 2 \mathrm{Z3}$, performing even better in aqueous ethanol than in pure ethanol. Considering the Ox 2 dye series, we see essentially a reversal of the threshold energies between the mesylate and zwitterionic variants in changing between ethanol and ethanol:water whereas there is little change in the tosylate salt. The mesylate variant does have a somewhat greater output in ethanol than the tosylate, but in ethanol:water this result is reversed in the more polar solvent. In part the explanation of these observations is based on the assumption that the zwitterion forms a dimer, and in the high dielectric medium of ethanol:water, the dimer formation is greatly reduced. In ethanol there is a strong secondary absorption band for Ox $2 \mathrm{Z} 3$ at $261 \mathrm{~nm}$ constituting over $35 \%$ by area of the $S_{1} \leftarrow S_{0}$ band. In ethanol:water this same band is only about $16 \%$ by area of the principal absorption band and in pure water $15.5 \%$. We also note the extreme stability of both the mesylate salt and the sulfopropyl zwitterion in both ethanol and ethanol:water under argon. In neither case did we detect any degradation under the test conditions which varied between 1.5 and 4.5 million shots at $10 \mathrm{~J}$ input at $25 \mathrm{~Hz}$. The tosylate salt has a significantly reduced lifetime in ethanol:water leading one to suspect the tosylate anion to be more easily subject to photochemical degradation than the mesylate anion or the zwitterion.

The structural effects of auxochromes directly attached to the oxazole ring are seen in the series $\mathrm{Ox} 12,15,17,{ }^{3}$ and $\mathrm{Ox} 17 \mathrm{~A}$. In this group the phenyl ring has been rigidized either in plane or out of plane with respect to the oxazole ring. Generally 

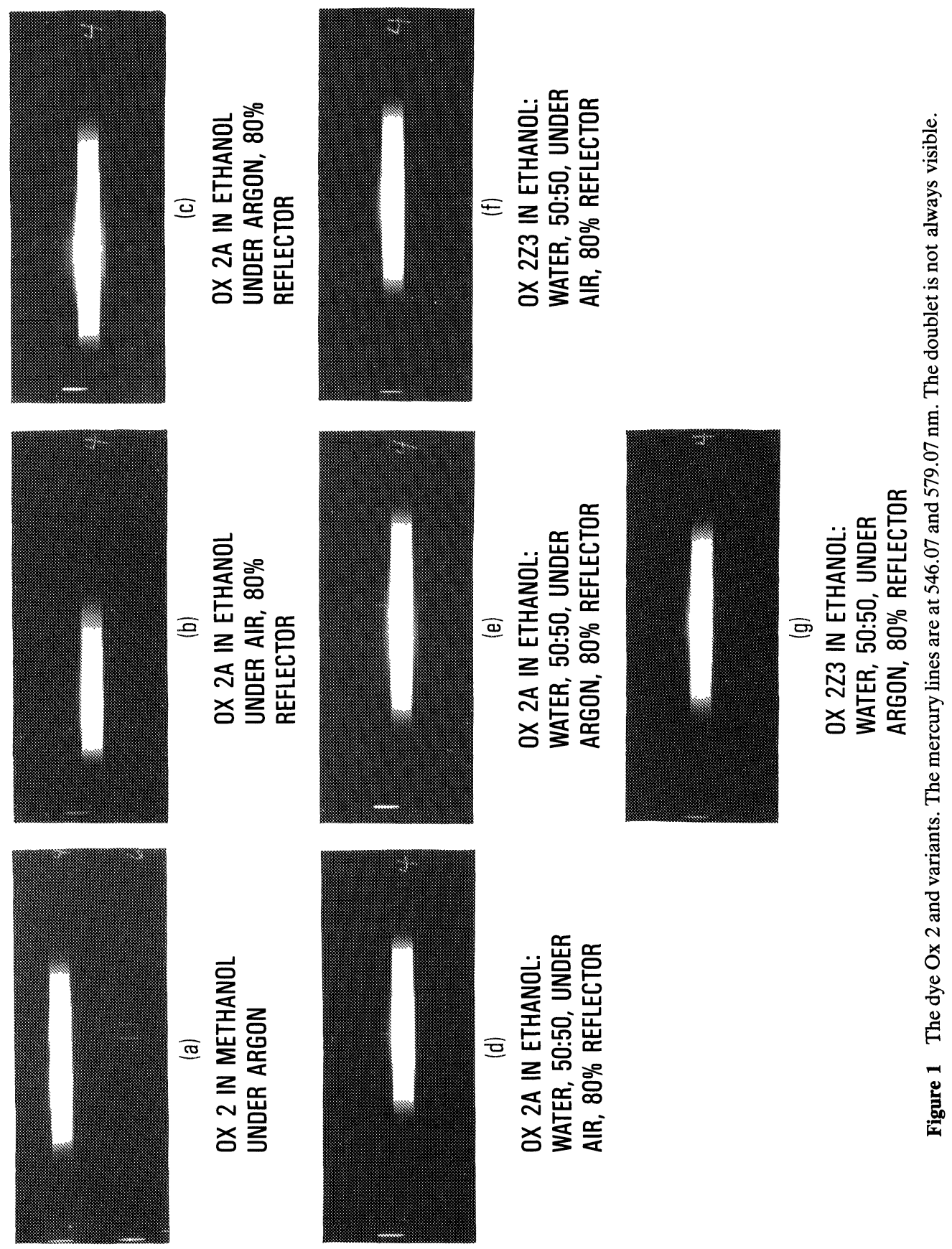

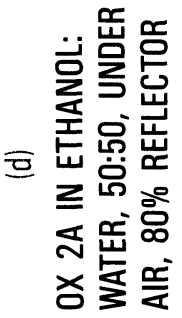



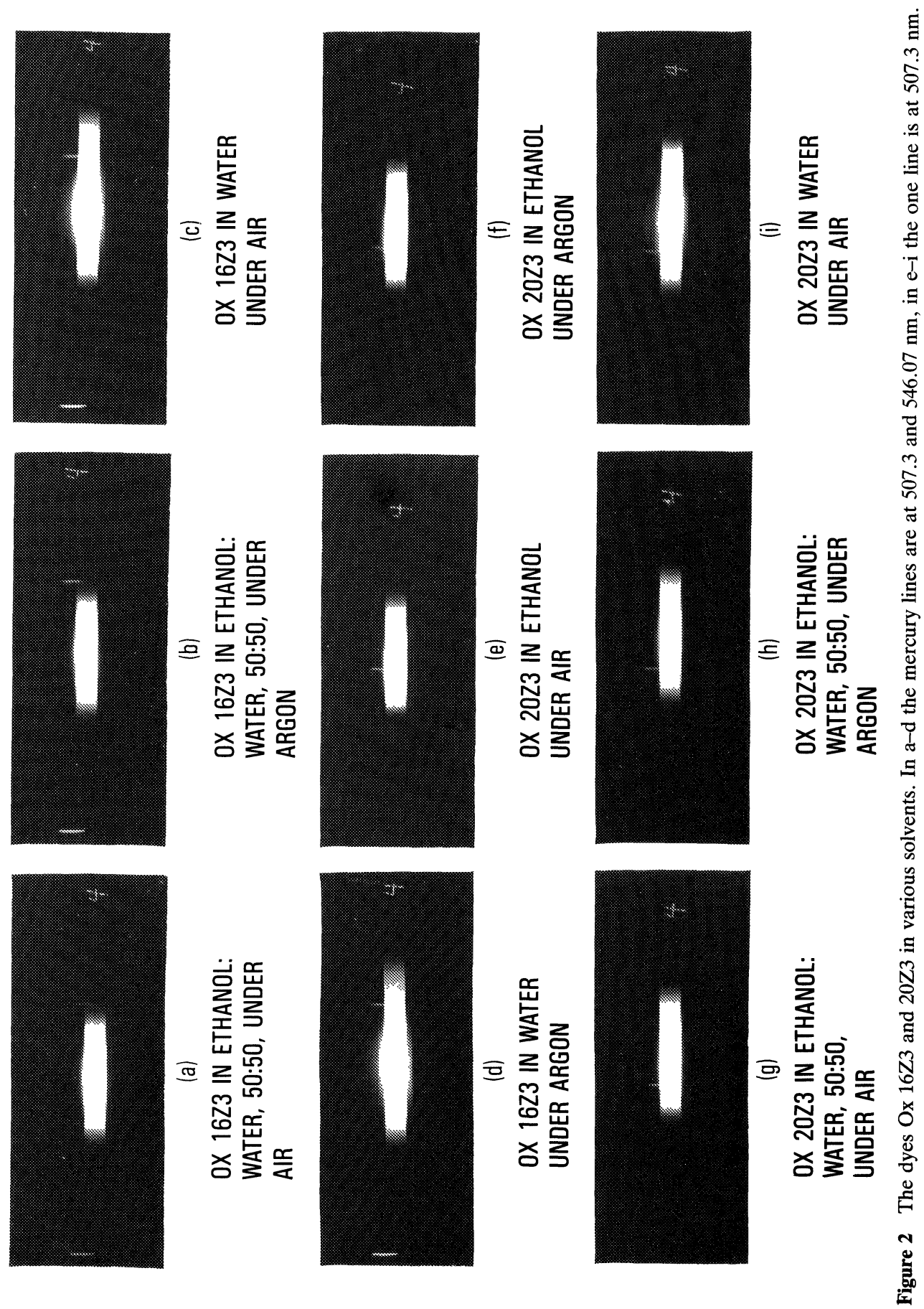


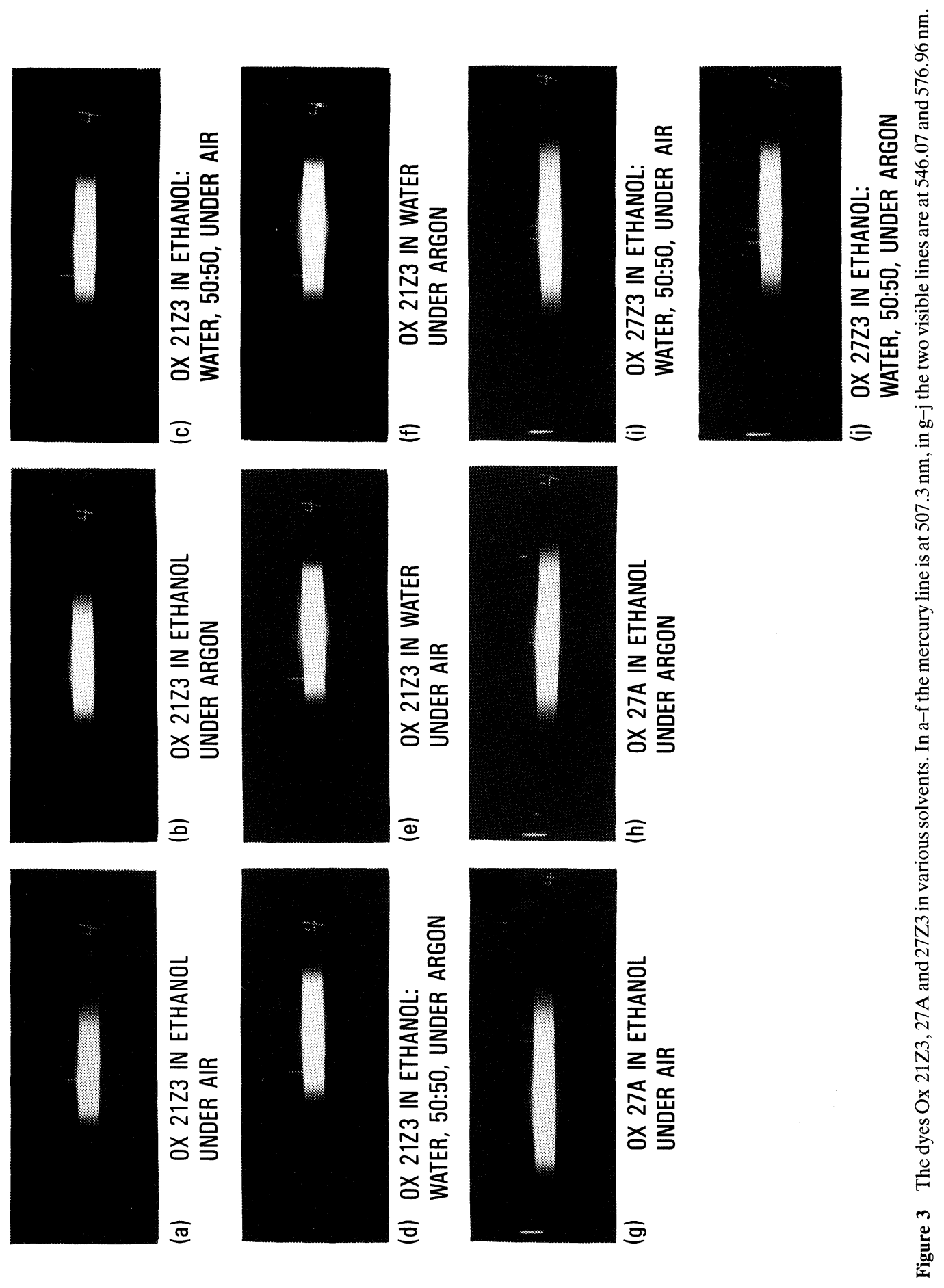




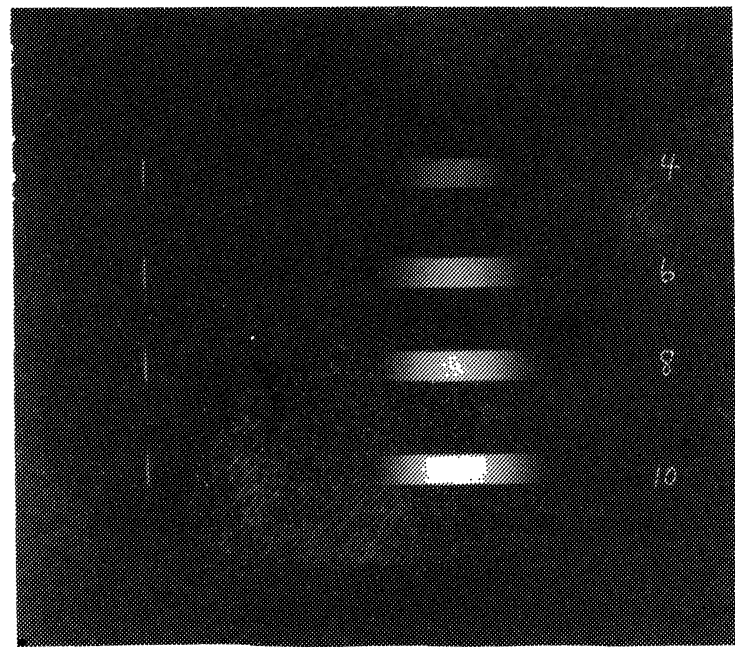

Figure 4 A series of single shots at 35, 40, 50 and $60 \mathrm{~J}$ input energies for the dye Ox $16 \mathrm{Z} 3$.

increasing the planarity of the $\pi$ electron system should improve the dye. This series shows mixed results with large variations in the photophysical properties. Ox 12 with an ethylene bridge between the phenyl and oxazole rings, and therefore not planar, has the largest slope efficiency of any dye we have measured. Its lifetime is short and its fluorescence quantum yield is quite low. Ox 15 forces planarity with a vinylene bridge between the phenyl and oxazole rings. This dye is one of those exhibiting a very long lifetime like $O x 2$ but with somewhat reduced slope efficiency. Ox 17 has two phenyl groups attached at the 4 and 5 positions on the oxazole ring. These are certainly not planar with themselves nor with the oxazole ring. The dye has a low slope efficiency and the lifetime is not useful. Forcing planarity in this enlarged $\pi$ electron system by a $2,2^{\prime}$ bond between the phenyl rings in Ox 17A produced a dye with a high fluorescence quantum yield but with low slope efficiency and extremely short lifetime. This extended system appears subject to rapid photochemical decomposition. Because of this observation only the quantum fluorescence yields of $\mathrm{Ox}$ 17AA and Ox 17AZ3 were measured.

Expanding the number of dyes considered to more than just the $\mathrm{Ox} 2$ series used by $\mathrm{K}-\mathrm{B}$, we find mixed results compared to the relative dye output ordering in their work. In Table 1 of Ref. 3, the first entry for Ox 13 is for the perchlorate salt, all remaining Ox 13 results are for the tosylate salt. The ratio of the slope efficiencies shows the perchlorate to have a little over $12 \%$ greater slope. ${ }^{8} \mathrm{~A}$ similar result is given in Ref. 1 with respect to differences between perchlorate and tosylate slope efficiencies. In Table 3 the difference in slope efficiencies between Ox 17 and 17A is somewhat larger but we have solvent effects entering. Here the tosylate salt (Ox 17A) has poor photochemical stability in ethanol:water. Thus, in the polar solvents we are using, we have found only relatively small differences in output between tosylate and perchlorate salts of the pyridinium oxazole dyes. If we are comparing the energy output, we would now add mesylate salts as having only small differences from the former two. 
Of the four other zwitterionic dye variants tested (Table 2), only one had a higher output than its tosylate analog. Ox $16 \mathrm{Z} 3$ has an output twice Ox 16 but its lifetime is reduced to a low level. Comparson with Ox $21 Z 3$ and Ox 21, where the ethylene bridge has been replaced by a methyl group on the oxazole ring 4 position, shows a moderate output dye with a greatly improved lifetime for Ox $21 \mathrm{Z3}$ over Ox $16 \mathrm{Z3}$ though Ox 21 is still the better dye.

Again, in the dye Ox $20 \mathrm{Z} 3$ we see increased output in changing solvents from ethanol to ethanol:water. This dye also showed the extreme photostability of Ox 2Z3. The lasing parameters of Ox $27 \mathrm{~A}$ and $\mathrm{Ox} 27 \mathrm{Z} 3$ were not measured. This $n$-butoxy substitution in position $\mathrm{C}$ was originally made to try to increase solubility; again, the zwitterion variant had less output than the mesylate salt. We have found that for most of the dyes studied, ethanol:water under argon gives the maximum output (Table 3 ). The removal of oxygen has been shown to greatly improve the performance of some dyes. ${ }^{9}$ However, we note that the zwitterionic dye variants we have tried in water also lase well under air or argon though with shortened lifetimes and reduced output. From Figures 2 and 3, the lasing bands of Ox 16Z3, $20 \mathrm{Z3}$ and $21 \mathrm{Z3}$ in water are seen to be as broad as in more favorable solvents.

K-B also report that their laser output curves are bifurcated. We find no such effects in any of the dyes we have studied, not even when we have used the same solvent as K-B. They postulate the possibility of absorption by a higher excited triplet state. Perhaps an even more unlikely explanation for the apparent null in their spectra is absorption by a higher excited singlet state, which they also postulated. We do not believe it to be lasing at two different wavelengths, i.e., dual lasing, which has been reported for some dyes.

We note that several old pictures in our library did indicate an apparent null in the lasing bands of some dyes. At the start of this work this null appeared again. Comparison with our earlier work showed the null was located at the same wavelength irrespective of the dye and, therefore, was not associated with the dye. Replacement of the rear mirror with another wideband mirror having different coatings completely eliminated the null.

\section{References}

1. A. N. Fletcher, R. A. Henry, R. F. Kubin and R. A. Hollins, Optics Comm. 48, 352-356 (1984).

2. J. M. Kauffman and J. H. Bentley, Laser Chem. 8, 49-59 (1988).

3. A. N. Fletcher, R. A. Henry, M. E. Pietrak and D. E. Bliss, Appl. Phys. B43, 155-160 (1987).

4. A. N. Fletcher, D. E. Bliss, M. E. Pietrak and G. E. McManis III, Proceedings of the International Conference on Lasers '85, Las Vegas, 797 (1985).

5. J. M. Kauffman, private communication.

6. A. N. Fletcher, R. H. Knipe and M. E. Pietrak, Appl. Phys. B27, 93-97 (1982).

7. A. N. Fletcher, Appl. Phys. B31, 19-26 (1983).

8. The second entry for Ox 13 in Table 1 of reference 3 is partly in error. The slope should be 1.64 , threshold $22.5 \mathrm{~J}$, lifetime $3.2 \mathrm{MJ} / \mathrm{l}$, and FOM $5.2 \mathrm{~kJ} / 1$. Other parts of this entry are correct.

9. R. F. Kubin and A. N. Fletcher, Chem. Phys. Lett. 99, 49-52 (1983). 